\title{
Effects of Hyperventilation on Prostacyclin Formation and on Pulmonary Vasodilation after Group B $\beta$-Hemolytic Streptococci-Induced Pulmonary Hypertension
}

\author{
CATHY HAMMERMAN' AND MARY JANE ARAMBURO \\ Division of Newborn Medicine, The University of Chicago Medical Center, Chicago, Illinois 60637
}

\begin{abstract}
Prostacyclin is released during hyperventilation (HV); however, its role as mediator of $\mathrm{HV}$-induced pulmonary vasodilation remains controversial. We have investigated this by studying the effects of $\mathrm{HV}$ on pulmonary artery pressure (PAP) in otherwise normal lungs versus lungs vasoconstricted with group B streptococci (GBS), with and without prior prostacyclin synthesis inhibition. Two- to 3-wk-old piglets were given tranylcypromine, a prostacyclin synthetase inhibitor $(n=6)$, or placebo $(n=6)$. Animals were mechanically ventilated normally, then hyperventilated $\left(\mathrm{PCO}_{2} 1.5 \pm 0.2 \mathrm{kPa}\right)$ and then returned to normal ventilation. After each 30 -min segment, plasma 6-keto-prostaglandin $F_{1 \alpha}$ (6-keto-PGF $F_{1 \alpha}$ ) (prostacyclin hydrolysis product) levels and PAP were measured. Then GBS infusions were administered to both groups to induce pulmonary hypertension. With GBS, the normal ventilation/hyperventilation/normal ventilation protocol was repeated as above. Results are as follows: 1) $\mathrm{HV}$ of normal lungs caused release of 6-keto-PGF - $_{1 \alpha}(351 \pm 234$ to $873 \pm 310 \mathrm{pg} / \mathrm{mL} ; p<0.05)$, but PAP was unaffected $(1.4 \pm 0.2 \mathrm{kPa}) ; 2) \mathrm{HV}$ of lungs vasoconstricted with GBS caused a similar release of 6 -keto-PGF - $_{1 \alpha}(595 \pm 112$ to $977 \pm 216 \mathrm{pg} / \mathrm{mL} ; p<0.05)$, this time accompanied by a significant decrease in PAP (3.1 \pm 0.5 to $2.3 \pm 0.5 \mathrm{kPa} ; p$ $<0.05)$; 3) $\mathrm{HV}$ of normal lungs pretreated with tranylcypromine produced neither an increase in 6-keto-PGF ( $_{1 \alpha}(400$ \pm 24 to $436 \pm 33 \mathrm{pg} / \mathrm{mL})$ nor a decrease in PAP $(1.3 \pm$ 0.2 to $1.4 \pm 0.2 \mathrm{kPa}$; and 4$) \mathrm{HV}$ after tranylcypromine pretreatment and GBS-induced pulmonary hypertension also produced no change (6-keto-PGF $1: 527 \pm 54$ to 556 $\pm 93 \mathrm{pg} / \mathrm{mL}$ and PAP; $39.5 \pm 6.2$ to $37.6 \pm 6.7 \mathrm{kPa}$ ). In conclusion, prostacyclin may mediate $\mathrm{HV}$-induced pulmonary vasodilation after GBS-induced pulmonary hypertension. (Pediatr Res 29: 282-287, 1991)
\end{abstract}

\section{Abbreviations}

PAP, pulmonary artery pressure

GBS, group B $\beta$-hemolytic streptococci

PGF $_{1 \alpha}$, prostaglandin $\mathbf{F}_{1 \alpha}$

Tcp, tranylcypromine

PVR, pulmonary vascular resistance

AOP, aortic pressure

HR, heart rate

SVI, stroke volume index

$\mathbf{T x B}_{2}$, thromboxane $\mathbf{B}_{2}$

Received January 10. 1990; accepted November 11, 1990

Correspondence: Cathy Hammerman, M.D., Hadassah Hospital-Mount Scopus, P.O.B. 24035 , il 91240, Jerusalem, Israel

Currently at Hadassah Hospital-Mount Scopus.
Hyperventilation is able to alleviate the pulmonary vasoconstriction induced by hypoxia (1) and/or by the infusion of the thromboxane mimetic, U46 619 (2). Clinically, hyperventilation alkalosis has become a central component of the treatment of persistent pulmonary hypertension of the newborn (3), a syndrome characterized by persistent and excessive pulmonary vasoconstriction.

However, the mechanism by which hyperventilation induces pulmonary vasodilation remains controversial. Prostacyclin is a potent pulmonary vasodilator that is released during hyperventilation and has been proposed by some to play a mediating role (4-8). In this study, we examined the effects of hyperventilation on 6-keto-PGF ${ }_{1 \alpha}$ concentrations and on pulmonary artery pressure and on their interaction under various conditions. Our goals were to test the following hypotheses: 1 ) effects of hyperventilation on 6-keto-PGF - $_{1 \kappa}$ concentrations and on pulmonary artery pressure in otherwise normal lungs are similar to those observed in hyperventilation of GBS-infused lungs with prior pulmonary vasoconstriction and 2) the prostacyclin thus released does induce the accompanying pulmonary vasodilation.

This was studied via examination of hyperventilation-induced changes in normal newborn piglet lungs and in piglet lungs after GBS-induced pulmonary hypertension, with and without prior prostacyclin inhibition.

\section{MATERIALS AND METHODS}

Surgical preparation. Two- to 3-wk-old piglets Sus Scrofa were sedated with ketamine $(20 \mathrm{mg} / \mathrm{kg}$ intramuscularly) and then anesthetized with i.v. sodium pentobarbital $(20 \mathrm{mg} / \mathrm{kg}$ initially, $2 \mathrm{mg} / \mathrm{kg} / \mathrm{h}$ subsequently) and endotracheally intubated. Muscle relaxation was achieved with $d$-tubocurarine $(1 \mathrm{mg} / \mathrm{kg})$. Warming blankets and overhead thermal heating lamps were used to maintain body core temperature at $38-39^{\circ} \mathrm{C}$. A suprapubic cystotomy catheter was placed to establish urinary drainage in the paralyzed animal.

Two polyethylene catheters providing venous access were introduced surgically into the external jugular vein. Intravascular catheters attached to pressure transducers were placed in the aorta (via the carotid artery), the right atrium (via the external jugular vein), the left atrium (via the appendage), and the pulmonary artery (via a left lateral thoracotomy). An external electromagnetic flow probe (Carolina Medical Electronics, King, NC) was placed around the pulmonary artery, visualized via the left lateral thoracotomy, proximal to the tip of the pulmonary artery catheter. The ductus arteriosus was ligated at the completion of the surgical preparation.

During each experiment, the pulmonary artery flow probe was zeroed frequently using the approximation that diastolic blood flow in the pulmonary artery is zero. Mean pressures were obtained by electrical integration at 10 -min intervals. The following hemodynamic variables were measured directly: phasic and 
mean AOP, phasic and mean PAP, phasic and mean central venous pressure (CVP), phasic and mean left atrial pressure (LAP), pulmonary artery blood flow, and HR. In the assumed absence of right to left and left to right shunts, pulmonary artery blood flow was accepted as the equivalent of $\mathrm{CO}$. From these monitored hemodynamic values, systemic vascular resistance (SVR) was calculated as SVR $=(\mathrm{AOP}-\mathrm{CVP}) / \mathrm{CO}, \mathrm{PVR}$ was calculated as (PAP - LAP)/CO, CI (cardiac index) was calculated as $\mathrm{CO} / \mathrm{wt}$; and $\mathrm{SVI}$ as $\mathrm{CI} / \mathrm{HR}$.

Experimental protocol. The following experimental protocol was approved by the Institutional Animal Care Review Committee. Control hemodynamic measurements were taken and determined to be stable for at least $1 / 2 \mathrm{~h}$ after surgery in all animals. Piglets were ventilated with a fraction of inspired oxygen of 0.60 throughout the entire study to prevent any hypoxic component of the GBS infusion from independently affecting PAP (1).

Preparation of bacteria. GBS serotype $1 \mathrm{~b}$, previously isolated from an infected human newborn, were grown in $250 \mathrm{~mL}$ of Todd-Hewitt broth to late log phase $\left(\sim 1 \times 10^{9}\right.$ organisms $\left./ \mathrm{mL}\right)$. The bacteria were centrifuged, the supernatant decanted, and the organism resuspended to their original concentration in D5/ lactated Ringer's solution, GBS infusion rate was increased slowly in a stepwise manner from $0.5 \times 10^{7}$ organisms $/ \mathrm{kg} / \mathrm{min}$ to $10^{8}$ organisms $/ \mathrm{kg} / \mathrm{min}$.

$T c p$ sulfate. Tcp (Smith, Kline, French Labs, Philadelphia, PA) was prepared at a concentration of $20 \mathrm{mg} / \mathrm{mL}$ in normal saline. Tcp was administered to block prostacyclin synthesis at a dose of $20 \mathrm{mg} / \mathrm{kg} 30 \mathrm{~min}$ before any manipulation (4).

Protocols. Experiment 1: effects of hyperventilation on PAP and 6-keto-PGF $F_{1 \alpha}$ concentrations in normal lung. After stabilization, mechanical ventilation was adjusted in six animals to maintain an arterial $\mathrm{CO}_{2}$ tension of $3.4 \pm 0.4 \mathrm{kPa}$ (volumes ranged from 100 to $150 \mathrm{~mL}$; rates ranged from 15 to 20 breaths/ min) and was continued as such for $30 \mathrm{~min}$ in six animals. At the completion of this segment, and of each subsequent 30-min segment, mixed venous (from the pulmonary artery) blood samples were collected for the measurement of 6-keto-PGF 1 $_{1 \alpha}$ levels and arterial and mixed venous blood samples were collected for the measurement of blood gases and oxygen contents. Next, a 30-min segment of hyperventilation alkalosis was begun in which ventilation was adjusted to yield an arterial $\mathrm{CO}_{2}$ tension of 1.5 $\pm 0.4 \mathrm{kPa}$ and repeat blood samples were collected. The final segment consisted of a return to "normal" ventilation $\left(\mathrm{PCO}_{2} 3.4\right.$ $\pm 0.4 \mathrm{kPa}$ ), as described above and repeat blood sampling. Hemodynamic variables were monitored continuously in all animals, and the measurements taken at the end of each segment were selected for analysis and comparison to coincide with blood sampling.

Experiment 2: effects of hyperventilation on PAP and 6-keto$P G F_{1 \times}$ concentrations in lungs with GBS-induced pulmonary hypertension. In sequence to experiment 1, GBS were infused as described above until stable pulmonary hypertension, defined as an increase in PAP to $150-200 \%$ of baseline, was established and sustained for $30 \mathrm{~min}$. At this point, and as the GBS infusion continued, a repeat of the normal ventilation-hyperventilationnormal ventilation segments of the protocol described under phase 1 was performed with similar hemodynamic monitoring and blood sampling.

Experiment 3: effects of prostacyclin inhibition on baseline parameters of otherwise normal piglets. In a new group of six animals, stabilization and $30 \mathrm{~min}$ of baseline ventilation $\left(\mathrm{PCO}_{2}\right.$ $3.4 \pm 0.4 \mathrm{kPa}$ ) were achieved as above. Then, the prostacyclin synthetase inhibitor Tcp was administered to six animals while all of the hemodynamic parameters were measured and recorded. Blood gases were collected after $30 \mathrm{~min}$ of stabilization and again $30 \mathrm{~min}$ after administration of Tcp.

Experiment 4: effects of prostacyclin inhibition on PAP of normal lungs under conditions of hyperventilation. The normal ventilation-hyperventilation-normal ventilation segments of the protocol were performed on the above group of Tcp-pretreated animals. Hemodynamics were measured and recorded and blood samples collected.

Experiment 4: effects of hyperventilation on PAP in lungs with GBS-induced pulmonary hypertension under conditions of prostacyclin inhibition. The group of animals that had been pretreated with the prostacyclin inhibitor Tcp was also given infusions of GBS and the normal ventilation-hyperventilation-normal ventilation segments of the protocol were repeated under these conditions with similar hemodynamic monitoring and blood sampling.

Experiment 5: effects of hyperventilation on $P A P$ in lungs with $G B S$-induced pulmonary hypertension under conditions of prostacyclin inhibition. The group of animals that had been pretreated with the prostacyclin inhibitor Tcp was also given infusions of GBS and the normal ventilation-hyperventilation-normal ventilation segments of the protocol were repeated under these conditions with similar hemodynamic monitoring and blood sampling.

Six-keto-PGF $F_{1 \alpha}$ RIA. Plasma samples were assayed for levels of 6-keto-PGF ${ }_{1 \alpha}$, a stable metabolite of the vasodilator prostacyclin, and $\mathrm{TxB}_{2}$, a stable metabolite of the vasoconstrictor thromboxane $\mathrm{A}_{2}$. Three $\mathrm{mL}$ of blood were collected into heparinized $(100 \mathrm{U} / \mathrm{mL})$ syringes and immediately decanted into siliconized glass tubes containing a final concentration of indomethacin at $2 \times 10^{-5} \mathrm{M}$ and centrifuged at $2000 \times g$ at $4^{\circ} \mathrm{C}$ for $10 \mathrm{~min}$. The plasma was harvested and frozen at $-60^{\circ} \mathrm{C}$ pending analysis by RIA.

Duplicate samples were extracted with Waters Sep Pak cartridges and then incubated with tritiated tracer (New England Nuclear, Boston, MA) and antibody (Seragen Inc., Boston, MA) for $16-20 \mathrm{~h}$ at $4^{\circ} \mathrm{C}$. The free ligand was then adsorbed with dextran/charcoal solution and the radioactivity of the supernatant was measured in a liquid scintillation counter. Standard concentrations of the prostanoids (Sigma Chemical Co., St. Louis, MO) were used to generate standard curves by Logit transformation. The standards were diluted in plasmanate to simulate plasma with minimal basal prostaglandin levels. Nonspecific binding in plasmanate most closely approximates that of newborn plasma (9.6 versus $9.4 \%$, respectively, as compared with $13.1 \%$ for adult plasma and $4.6 \%$ for buffer). The accuracy of this method for detection of a known amount of prostaglandin added to plasmanate ranges from 92 to $114 \%$. Intraassay and interassay coefficients of variation were $5-15$ and $11-15 \%$, respectively. Minimum detectable levels were $50 \mathrm{pg} / \mathrm{mL}$. Values reported were the means of duplicate determinations performed on each sample.

Data analysis. Means \pm SD were computed for all measured variables within each experiment and phase (e.g. normal ventilation or hyperventilation). Differences for a given variable between phases were compared using repeated measures analysis of variance. Where a significant difference was noted, comparisons were made by $t$ test with Bonferroni correction for multiple comparisons. A $p<0.05$ was considered statistically significant.

\section{RESULTS}

There were six animals in each segment, with no differences noted in weights or any of the other variables measured at baseline.

Effects of hyperventilation on PAP and 6-keto-PGF $F_{1 \alpha}$ concentrations in normal lung. Hyperventilation of normal lungs, as described, was successful in producing a decrease in $\mathrm{PCO}_{2}$ and an increase in $\mathrm{pH} . \mathrm{PO}_{2}$ did not change significantly. PAP (Fig. 1) was unaffected, as were PVR, mean AOP, CO, HR, and SVI (Table 1). Mixed venous 6-keto-PGF ${ }_{1 \alpha}$ levels increased $(p<0.05$; Fig. 1) and $\mathrm{TxB}_{2}$ levels (Table 2) were unchanged.

Effects of hyperventilation on PAP and 6-keto-PGF $F_{1 \alpha}$ concentrations in lungs with GBS-induced pulmonary hypertension. GBS infusion successfully generated pulmonary hypertension in 
PAP (KPa)

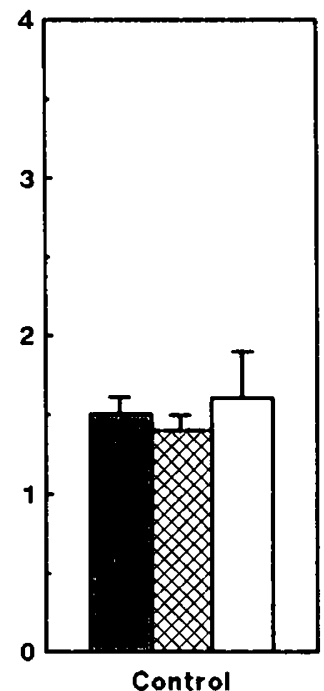

6 KETO PGF $1(\mathrm{pg} / \mathrm{ml})$

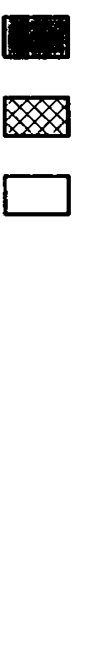

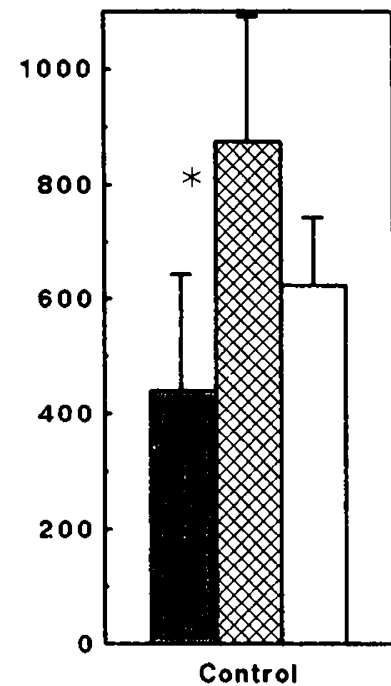

NORMAL VENT.

\section{HYPERVENTILATION}

JNORMAL VENT.

Fig. 1. PAP and 6-keto-PGF ${ }_{1 \alpha}$ of control piglets $(n=6)$ at baseline. The lefthand panel represents PAP in animals with otherwise normal lungs exposed to normal ventilation/hyperventilation/normal ventilation. There was no change in PAP. The righthand panel represent $6-\mathrm{keto} \mathrm{PGF} \mathrm{I}_{\boldsymbol{\alpha}}$ levels of the same group of animals. Levels of 6-keto-PGF $\mathrm{I}_{\mathrm{l}}$ were significantly increased by hyperventilation $(p<0.05)$.

Table 1. Hemodynamic variables in hyperventilated piglets with and without Tcp pretreatment before and after GBS infusions*

\begin{tabular}{|c|c|c|c|c|c|}
\hline & $\begin{array}{l}\text { AOP } \\
(\mathrm{kPa})\end{array}$ & $\begin{array}{l}\text { Cardiac index } \\
(\mathrm{mL} / \mathrm{kg} / \mathrm{min})\end{array}$ & $\begin{array}{c}\text { SVI } \\
(\mathrm{mL} / \mathrm{kg} / \text { beat }) \\
\end{array}$ & $\begin{array}{c}\mathrm{HR} \\
\text { (beats/min) }\end{array}$ & $\begin{array}{c}\text { PVR } \\
(\mathrm{kPa} / \mathrm{L} / \mathrm{kg} / \mathrm{min}) \\
\end{array}$ \\
\hline \multicolumn{6}{|l|}{ Control } \\
\hline Normal ventilation & $6.6 \pm 0.8$ & $130 \pm 36$ & $0.98 \pm 0.15$ & $131 \pm 25$ & $6.2 \pm 3.9$ \\
\hline Hyperventilation & $5.3 \pm 1.4$ & $127 \pm 57$ & $0.93 \pm 0.45$ & $137 \pm 22$ & $6.9 \pm 4.7$ \\
\hline Normal ventilation & $5.9 \pm 0.9$ & $108 \pm 56$ & $0.83 \pm 0.37$ & $129 \pm 25$ & $8.4 \pm 4.6$ \\
\hline \multicolumn{6}{|l|}{ Tcp } \\
\hline Baseline & $6.6 \pm 1.0$ & $159 \pm 34$ & $1.20 \pm 0.30$ & $133 \pm 14$ & $3.8 \pm 0.8$ \\
\hline Normal ventilation & $5.5 \pm 1.2$ & $149 \pm 49$ & $0.94 \pm 0.39$ & $165 \pm 26 \dagger$ & $4.7 \pm 1.6$ \\
\hline Hyperventilation & $4.7 \pm 0.5$ & $128 \pm 49$ & $0.75 \pm 0.31$ & $174 \pm 12 \dagger$ & $6.2 \pm 3.9$ \\
\hline Normal ventilation & $6.3 \pm 0.9$ & $129 \pm 44$ & $0.78 \pm 0.30$ & $170 \pm 15 \dagger$ & $5.5 \pm 3.1$ \\
\hline \multicolumn{6}{|l|}{ Control/GBS } \\
\hline Normal ventilation & $6.7 \pm 0.8$ & $82 \pm 30$ & $0.61 \pm 0.24 \ddagger$ & $138 \pm 20$ & $32.8 \pm 15.6 \ddagger$ \\
\hline Hyperventilation & $5.6 \pm 2.2$ & $81 \pm 33$ & $0.50 \pm 0.07$ & $156 \pm 38$ & $23.2 \pm 10.1 \ddagger \S$ \\
\hline Normal ventilation & $6.5 \pm 0.6$ & $62 \pm 26$ & $0.48 \pm 0.22$ & $128 \pm 12$ & $35.1 \pm 15.0 \ddagger$ \\
\hline \multicolumn{6}{|l|}{ Tcp/GBS } \\
\hline Normal ventilation & $7.8 \pm 1.6$ & $132 \pm 55$ & $0.82 \pm 0.30$ & $160 \pm 14$ & $23.0 \pm 10.4 \|$ \\
\hline Hyperventilation & $6.4 \pm 1.4$ & $113 \pm 48$ & $0.65 \pm 0.26$ & $172 \pm 19$ & $25.6 \pm 11.6 \|$ \\
\hline Normal ventilation & $6.3 \pm 1.1$ & $118 \pm 52$ & $0.60 \pm 0.30$ & $167 \pm 16 \pi$ & $27.5 \pm 15.6 \|$ \\
\hline
\end{tabular}

* Means \pm SD are presented. Baseline, in Tcp group, represents time before Tcp administration with normal ventilation. Baseline values are not different from corresponding values in control piglets before GBS infusion.

$\dagger p<0.05$ as compared with corresponding values before Tcp administration.

$\ddagger p<0.05$ as compared with corresponding control values before GBS.

$\S p<0.05$ as compared with corresponding values before hyperventilation.

$\| p<0.05$ as compared with corresponding values in Tcp piglets before GBS.

I $p<0.05$ as compared with corresponding values in control piglets with GBS infusions running, but without Tcp pretreatment.

all animals (PAP from $1.6 \pm 0.4$ to $3.1 \pm 0.5 \mathrm{kPa}$ ). Here again, hyperventilation produced a significant decrease in $\mathrm{PCO}_{2}$ and an increase in $\mathrm{pH}$ (Table 2). PAP in these previously vasoconstricted lungs was reduced by hyperventilation $(3.1 \pm 0.5$ to $2.3 \pm 0.5$ $\mathrm{kPa} ; p<0.05$; Fig. 2), as was PVR. Mean AOP, CO, HR, and SVI (Table 1) were not significantly affected by hyperventilation, although some were affected by the GBS infusions themselves, and thus were different than corresponding values in normal lungs. Mixed venous 6-keto-PGF ${ }_{1 \alpha}$ levels again increased with hyperventilation $(p<0.05)$ (Fig. 2); $\mathrm{TxB}_{2}$, on the other hand, were not affected by hyperventilation (Table 2) but were increased by the GBS infusions.

Effects of prostacyclin inhibition on baseline parameters of otherwise normal piglets. Only HR was significantly increased by administration of the prostacyclin inhibitor, Tcp. Other vari- ables monitored were not affected by the administration of Tcp (Table 1). Furthermore, these baseline values were not different from the baseline values in the control piglets. Neither 6-keto$\mathrm{PGF}_{1 \alpha}$ nor $\mathrm{TxB}_{2}$ (Table 2) were affected by Tcp administration.

Effects of prostacyclin inhibition on PAP of normal lungs under conditions of hyperventilation. Hyperventilation of Tcp-pretreated lungs was equally successful in reducing $\mathrm{PCO}_{2}$ and increasing $\mathrm{pH}$ (Table 2). PAP was unaffected by hyperventilation (Fig. 3), as were PVR, mean AOP, CO, HR, and SVI (Table 1). These values were not different from those observed in the control animals with hyperventilation.

However, in marked contrast to the nonpretreated piglets, mixed venous 6-keto-PGF ${ }_{1 \alpha}$ levels of the Tcp-treated piglets did not increase with hyperventilation (Fig. 4). $\mathrm{TxB}_{2}$ levels were unaffected. 
Table 2. Laboratory values for hyperventilated piglets*

\begin{tabular}{|c|c|c|c|c|}
\hline & $\mathrm{pH}$ & $\begin{array}{c}\mathrm{PO}_{2} \\
(\mathrm{kPa}) \\
\end{array}$ & $\begin{array}{l}\mathrm{PCO}_{2} \\
(\mathrm{kPa}) \\
\end{array}$ & $\begin{array}{c}\mathrm{TxB}_{2} \\
(\mathrm{pg} / \mathrm{mL}) \\
\end{array}$ \\
\hline \multicolumn{5}{|l|}{ Control } \\
\hline Normal ventilation & $7.36 \pm 0.906$ & $1.5 \pm 0.8$ & $3.4 \pm 0.6$ & $149 \pm 47$ \\
\hline Hyperventilation & $7.59 \pm 0.05 \dagger$ & $1.7 \pm 0.7$ & $1.5 \pm 0.2 \dagger$ & $182 \pm 65$ \\
\hline Normal ventilation & $7.34 \pm 0.09$ & $1.5 \pm 0.8$ & $3.3 \pm 0.9$ & $164 \pm 55$ \\
\hline \multicolumn{5}{|l|}{ Tcp } \\
\hline Normal ventilation & $7.38 \pm 0.06$ & $1.9 \pm 0.8$ & $3.3 \pm 0.5$ & $179 \pm 78$ \\
\hline Hyperventilation & $7.63 \pm 0.06 \dagger$ & $2.0 \pm 0.8$ & $1.5 \pm 0.5 \dagger$ & $203 \pm 88$ \\
\hline Normal ventilation & $7.41 \pm 0.10$ & $1.8 \pm 0.9$ & $3.0 \pm 0.9$ & $223 \pm 100$ \\
\hline \multicolumn{5}{|l|}{ Control/GBS } \\
\hline Normal ventilation & $7.27 \pm 0.07 \ddagger$ & $1.5 \pm 0.5$ & $3.7 \pm 0.5$ & $1001 \pm 246 \ddagger$ \\
\hline Hyperventilation & $7.58 \pm 0.10 \dagger$ & $1.7 \pm 0.5$ & $1.4 \pm 0.5 \dagger$ & $1260 \pm 86 \ddagger$ \\
\hline Normal ventilation & $7.27 \pm 0.06 \ddagger$ & $1.3 \pm 0.5$ & $3.4 \pm 0.5$ & $1423 \pm 93 \ddagger$ \\
\hline \multicolumn{5}{|l|}{ Tcp/GBS } \\
\hline Normal ventilation & $7.34 \pm 0.08$ & $1.8 \pm 0.3$ & $3.4 \pm 0.9$ & $879 \pm 280 \ddagger$ \\
\hline Hyperventilation & $7.58 \pm 0.09 \dagger$ & $1.9 \pm 0.2$ & $1.6 \pm 0.7 \dagger$ & $1047 \pm 411 \ddagger$ \\
\hline Normal ventilation & $7.35 \pm 0.09$ & $1.5 \pm 0.5$ & $3.0 \pm 0.8$ & $1026 \pm 493 \ddagger$ \\
\hline
\end{tabular}

* Means $\pm \mathrm{SD}$ are presented. All animals demonstrated decreased $\mathrm{PCO}_{2}$ with hyperventilation, none showed significant changes in oxygenation, and only the control animals developed acidosis with GBS infusion.

$\dagger p<0.05$ as compared with corresponding values before hyperventilation.

$\ddagger p<0.05$ as compared with corresponding control before GBS.

PAP (KPa)

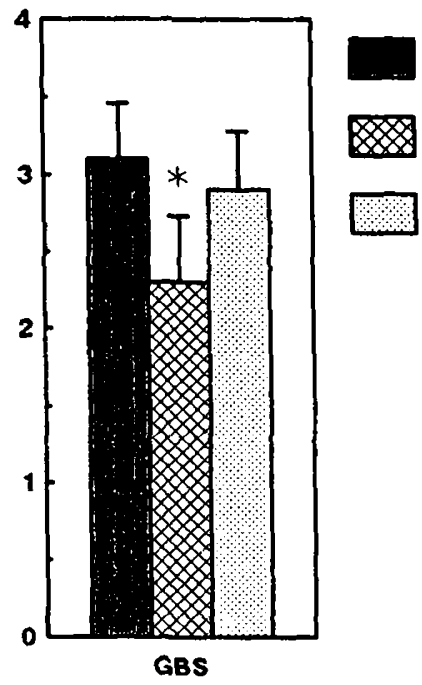

6 KETO PGF $1(\mathrm{pg} / \mathrm{ml})$

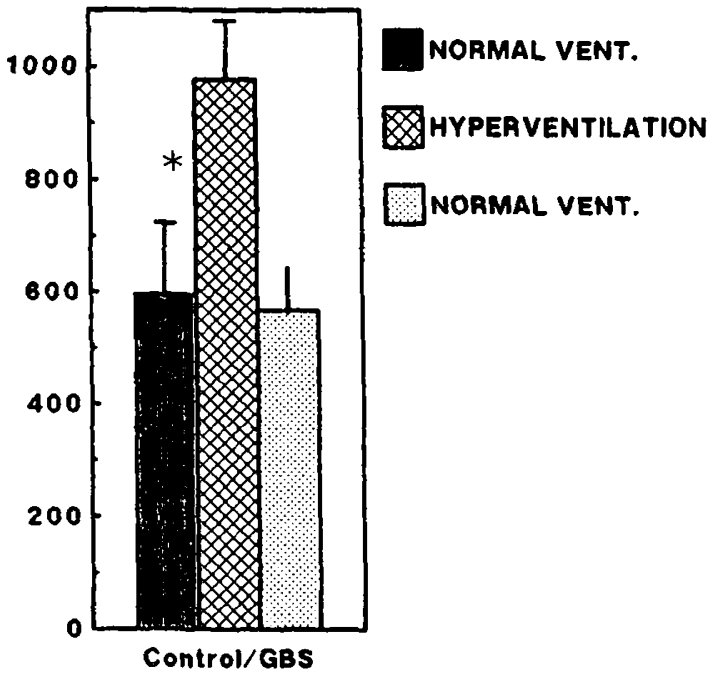

Fig. 2. PAP and 6-keto-PGF $F_{1 \alpha}$ of the same group of animals after GBS infusion induced pulmonary hypertension. They were again exposed to the hyperventilation protocol. The lefthand panel represents PAP and PAP was significantly reduced $(p<0.05)$ by hyperventilation. All of the PAP in this panel are significantly different from the corresponding values at baseline $(p<0.05)$. The righthand panel represents $6-\mathrm{keto} \mathrm{PGF}_{\mathrm{ta}}$ levels, which were significantly increased by hyperventilation $(p<0.05)$.

Effects of hyperventilation on PAP in lungs with GBS-induced pulmonary hypertension under conditions of prostacyclin inhibition. GBS infusion generated pulmonary hypertension in the Tcp animals as well. Here again, hyperventilation produced a significant decrease in $\mathrm{PCO}_{2}$ and an increase in $\mathrm{pH}$ (Table 2). However, in contrast to the noninhibited GBS-infused animals, hyperventilation here did not produce a significant decrease in PAP, even though these lungs were vasoconstricted (Fig. 5). PVR, mean AOP, CO, HR, and SVI (Table 1) were not significantly affected by hyperventilation, although several of these were affected by the GBS infusions themselves, and thus were different than corresponding values in normal lungs. Mixed venous 6-keto$\mathrm{PGF}_{1 \mathrm{r}}$ and $\mathrm{TxB}_{2}$ levels here again did not increase with hyperventilation (Fig. 6); however, $\mathrm{TxB}_{2}$ levels (Table 2 ) were increased by the GBS itself.

\section{DISCUSSION}

Prostacyclin is a potent dilator of the pulmonary circulation $(5-9)$. In the animal, the onset of breathing at birth increases plasma concentrations of the prostacyclin metabolite, 6-keto$\mathrm{PGF}_{1 \alpha}(10)$, and pretreatment with indomethacin blunts both the release of 6-keto-PGF ${ }_{1 \alpha}$ and the drop in PVR (11).

Hyperventilation has been shown to be able to induce pulmonary vasodilation even beyond the initiation of respiration at birth. Respiratory alkalosis can reduce hypoxic pulmonary vasoconstriction (1) and reduce PAP iatrogenically elevated via the infusion of the thromboxane mimetic U46619 (2). Human neonates with persistent pulmonary hypertension of the newborn are hyperventilated clinically in attempt to selectively reduce pulmonary vasoconstriction (3).

We have examined the role of prostacyclin release in hyperventilation-induced pulmonary vasodilation in the context of pulmonary hypertension. When PAP has been abnormally elevated, hyperventilation induces a decrease in PAP. However, in normally ventilated lungs without prior vasoconstriction, we detected no pulmonary vasodilating effect of hyperventilation. There are many discrepant reports in the literature on this issue. 


\section{PAP (KPa)}

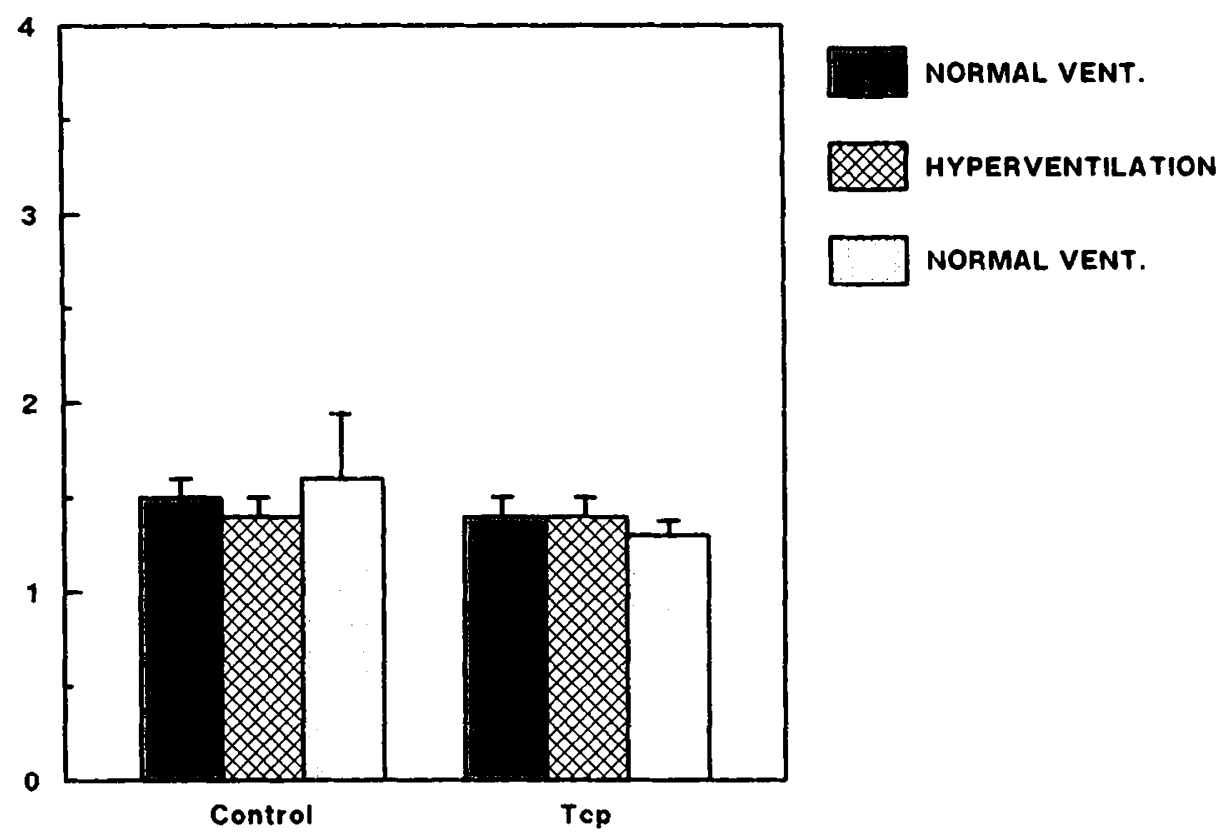

Fig. 3. PAP of Tcp-treated piglets $(n=6)$ as compared with control piglets. As before, the animals were exposed to normal ventilation/ hyperventilation/normal ventilation. The lefthand panel represents the control animals at baseline, and the righthand panel represents the Tcptreated animals. In both groups of animals, there was no change in PAP with hyperventilation.

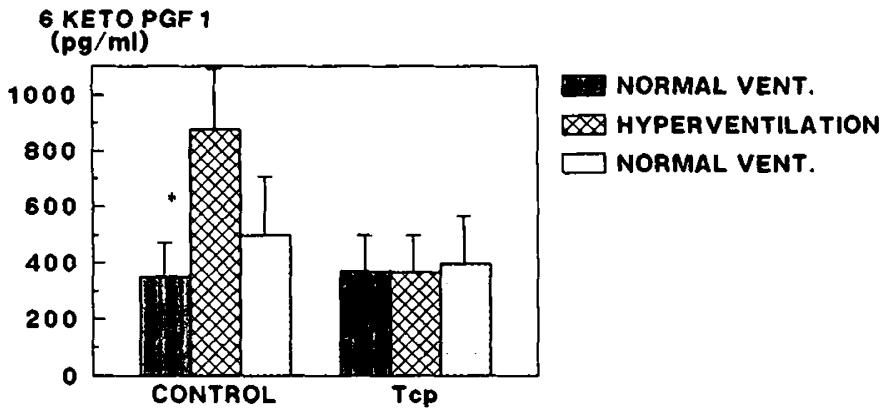

Fig. 4. Levels of 6-keto-PGF $F_{1 a}$ in Tcp-treated piglets $(n=6)$ as compared with control piglets. As before, the animals were exposed to normal ventilation/hyperventilation/normal ventilation. The lefthand panel represents the control animals at baseline and the righthand panel represents the Tcp-treated animals. In the control animals, there was a significant increase in 6-keto-PGF ${ }_{1 \alpha}$ whereas in the Tcp animals, 6-keto$\mathrm{PGF}_{1 \pi}$ levels were not increased by hyperventilation.

Fike and Hansen (1), for instance, report that respiratory alkalosis decreases PAP during normoxia. However, their normoxia follows a hypoxic insult. Despite the further reduction generated in PAP, PAP in their study does not fall significantly below initial baseline values. Thus, the vasodilator effect may still occur only in lungs with previously elevated pulmonary vascular tone. Morin (12) also observed that hyperventilation reduced PAP in normal lungs. These findings contrast not only with our results, but also with those of several studies performed in adult animals with normal pulmonary circulation in whom direct effects of respiratory alkalosis on PAP have been found to be small or insignificant (13-15). However, Morin's PAP during normal ventilation appears (from his graph) to be around 26 torr, which seems to be a somewhat elevated baseline. If so, Morin's data may also be consistent with the hypothesis that hyperventilation is effective on lungs previously vasoconstricted.

Hyperventilation is known to lead to the release of prostacyclin from the lungs $(16-18)$. $\mathrm{PGI}_{2}$, in turn, is a potent pulmonary vasodilator of fetal and newborn lung $(6,7,9)$. Prostacyclin has

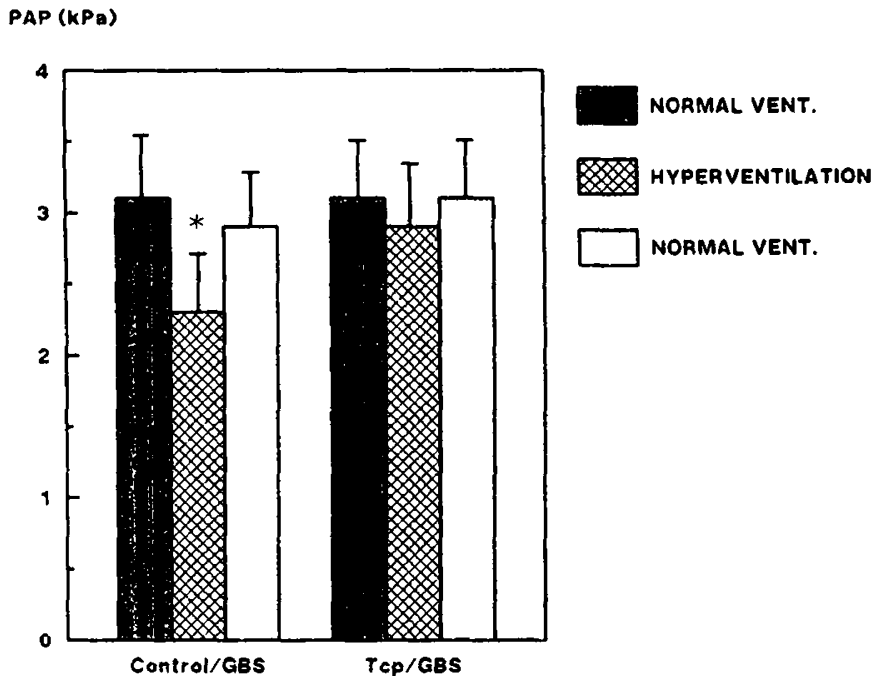

Fig. 5. PAP of control vs. Tcp-treated piglets subjected to hyperventilation after exposure to GBS-induced pulmonary hypertension. The lefthand panel demonstrates a significant $(p<0.05)$ decrease in PAP in the control animals with hyperventilation, as compared with no change in PAP in the Tcp animals (righthand panel) subjected to the same protocol.

been proposed, therefore, as the mediator of hyperventilationinduced pulmonary vasodilation.

We feel that the current data, by demonstrating that eliminating the hyperventilation-associated release of $6-$ keto-PGF $_{1 \alpha}$ also eliminates the hyperventilation-associated reduction in PAP, provide clear evidence of the critical role played by prostacyclin in mediating these changes.

Again, in apparent contrast to our findings, Morin (12) demonstrated, in newborn lambs, that respiratory alkalosis had similar effects on PAP whether or not the animals were pretreated with indomethacin. Thus, although he did detect an increase in the prostacyclin metabolite 6-keto-PGF ${ }_{1 \alpha}$ levels with hyperven- 


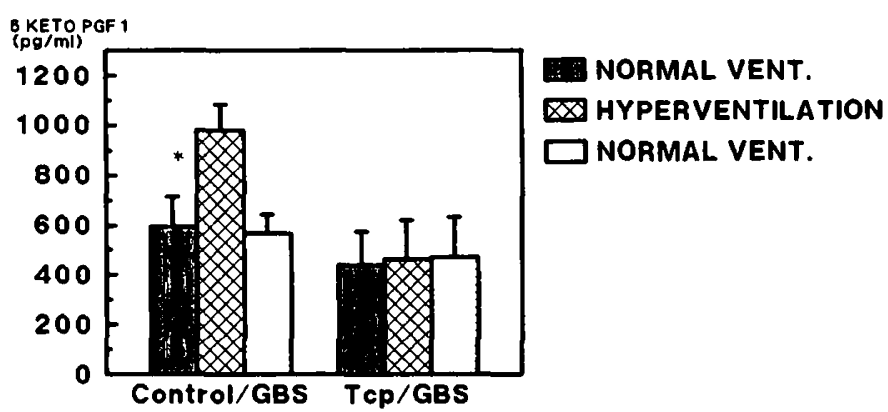

Fig. 6. Levels of 6-keto-PGF ${ }_{1 \alpha}$ in control vs. Tcp-treated piglets subjected to hyperventilation after exposure to GBS-induced pulmonary hypertension. The lefthand panel demonstrates a significant $(p<0.05)$ increase in 6-keto-PGF ${ }_{1 x}$ levels in the control animals with hyperventilation as compared with no change in 6-keto-PGF ${ }_{10}$ levels in the Tcp animals (righthand panel) subjected to the same protocol.

tilation, they concluded that prostacyclin was not mediating the hyperventilation effects. This appears to contradict our results; however, it is also possible that pulmonary hypertension of different etiologies reacts differently. Clearly, there are different mediators of hypoxic versus septic pulmonary hypertension (19) and septic pulmonary hypertension is attenuated by indomethacin (20), whereas hypoxic pulmonary hypertension is not responsive to indomethacin (21). It does not seem unreasonable, therefore, to assume that they may also respond in varying fashions to hyperventilation. Another possibility is that our use of a prostacyclin-specific synthetase inhibitor, as opposed to a general cyclooxygenase inhibitor, enabled us to more specifically block the vasodilator effects of prostacyclin. For instance, it has been shown that lung irritants, e.g. hyperoxia $(22,23)$ or sepsis $(24,25)$, are associated with increased thromboxane release. Indomethacin therefore may, by concurrently blocking some prostanoid-mediated balancing vasoconstrictive forces, have unmasked a secondary mechanism of hyperventilation-induced vasodilation. It has also been speculated that the use of a prostacyclin synthetase-specific inhibitor might do the reverse, i.e. divert the arachidonic acid cascade toward increased synthesis of other components, including thromboxane. If this were true, might thromboxane thereby released have accounted for the absence of pulmonary vasodilation? This seems unlikely in our system, inasmuch as we found no evidence of increased thromboxane metabolite levels in our Tcp-treated animals.

Of note is the fact that the Tcp-pretreated animals did not develop the GBS-induced metabolic acidosis seen in the control animals with GBS infusions. This finding appears to indicate that prostacyclin inhibition provided some protection against sepsis-associated acidosis. Although our study was not designed to evaluate the mechanisms involved, this is nevertheless an interesting observation worthy of further investigation.

In summary, the current data demonstrate that, in newborn piglets: $l$ ) with normally ventilated lungs, not previously vasoconstricted, hyperventilation does stimulate release of prostacyclin, as measured by levels of the metabolite, 6-keto-PGF $F_{1 x}$. However, this prostacyclin release does not affect baseline PAP. 2) After GBS-induced vasoconstriction, hyperventilation leads to an increase in 6-keto-PGF ${ }_{1 k}$ concentrations that is accompanied by a reduction in PAP. 3) Pretreatment with the prostacyclin synthetase inhibitor, Tcp, followed by GBS-induced pulmonary hypertension abolishes both the release of prostacyclin and the pulmonary vasodilation in response to subsequent hyperventilation.
These findings lead us to conclude that prostacyclin does in fact mediate hyperventilation-induced pulmonary vasodilation. However, it appears to require some combination of the presence of a vasodilator-mediating substance together with a pulmonary vasculature that has previously undergone certain types of vasoconstriction to effectively reduce PAP. Such a combination mechanism could explain the lack of pulmonary vasodilating effect despite the rise in prostacyclin metabolite levels in the normal lung animals.

\section{REFERENCES}

1. Fike C. Hansen 1989 The effect of alkalosis on hypoxia-induced pulmonary vasoconstriction in lungs of newborn rabbits. Pediatr Res 25:383-388

2. Redding G, Gibson R, Davis C, Truog W 1988 Effects of respiratory alkalosis on thromboxane-induced pulmonary hypertension in piglets. Pediatr Res 24:558-562

3. Drummond W, Gregory G, Heymann M, Phibbs R 1981 The independent effects of hyperventilation, tolazoline, and dopamine on infants with persistent pulmonary hypertension. J Pediatr 98:603-611

4. Farley D, VanOrden D 1982 Effect of prostacyclin inhibition by tranylcypromine on uterine 6 keto $\mathrm{PGF}_{\mathrm{b}}$, levels during estrogen hyperemia in rats. Prostaglandins 23:657-674

5. Cassin S 1980 Role of the prostaglandins and thromboxanes in the control of the pulmonary circulation in the fetus and newborn. Semin Perinatol 4:101107

6. Cassin S, Winkor I, Tod M, Phillips J, Frisinger J, Jordan J, Gibbs C 1981 Effects of prostacyclin on the fetal pulmonary circulation. Pediatr Pharmacol 1:197-207

7. Leffler C, Hessler J 1979 Pulmonary and systemic effects of exogenous prostaglandin 12 in fetal lambs. Eur J Pharmacol 54:37-42

8. Lock J, Olley P, Coceani F 1980 Direct pulmonary vascular responses to prostaglandins in the conscious newborn lamb. Am J Physiol 238:H631H638

9. Green R, Rojas J, Sundell H 1979 Pulmonary vascular response to prostacyclin in fetal lambs. Prostaglandins 18:927-934

10. Leffler C. Hessler J, Terragno N 1980 Ventilation induced release of prostaglandinlike material from fetal lungs. Am J Physiol 238:H282-H286

11. Lefler C, Tyler T, Cassin S 1978 Effect of indomethacin on pulmonary vascular response to ventilation of fetal goats. Am J Physiol 234:H346-H35 I

12. Morin III F 1986 Hyperventilation, alkalosis, prostaglandins and pulmonary circulation of the newborn. J Appl Physiol 61:2088-2094

13. Malik A, Kidd B 1973 The independent effects of changes in $\mathrm{H}^{+}$and $\mathrm{CO}_{2}$ concentrations on pulmonary hemodynamics of intact dogs. Can J Physiol Pharmacol 51:134-147

14. Robinson C, Holt J 1982 Inactivation of prostaglandins in the perfused rat lung. Biochem Pharmacol 31:633-638

15. Shapiro B, Simmons D, Linde L 1966 Pulmonary hemodynamics during acute acid base changes in the intact dog. Am J Physiol 210:1026-1032

16. Gryglewski R, Korbut R, Ocetkiewicz A, Splawinsk J, Wojtaszek B, Swies J 1978 Lungs as a generator of prostacyclin-hypothesis on physiological significance. Naunyn-Schmiedebergs Arch Pharmacol 304:45-50

17. Korbut R, Boyd J, Eling $\Upsilon 1981$ Respiratory movements alter the generation of prostacyclin and thromboxane $A_{2}$ in isolated rat lungs: the influence of arachidonic acid pathway inhibitors on the ratio between pulmonary prostacyclin and thromboxane $A_{2}$. Prostaglandins 21:491-503

18. Lefmer C. Hessler J, Terragno N 1980 Ventilation induced release of prostaglandin-like material from fetal lungs. Am J Physiol 238:H282-H286

19. Hammerman C, Komar K, Abu-Khudair H 1988 Hypoxic vs septic pulmonary hypertension: selective role of thromboxane mediation. Am J Dis Child 142:319-325

20. Rojas J, Larsson L, Ogletree M. Brigham K. Stahlman M 1983 Effects of cyclooxygenase inhibition on the response to group B streptococcal toxin in sheep. Pediatr Res 17:107-110

21. Walker B, Voelkel N, Reeves J 1982 Pulmonary pressor response after prostaglandin synthesis inhibition in conscious dogs. J Appl Physiol 52:705-709

22. Hageman J, Babler S, Lee S, Cobb M, Pachman L, Smith L. Hunt C 1986 The early involvement of pulmonary prostaglandins in hyperoxic lung injury. Prostaglandins Leukotrienes Med 25:105-122

23. Durante W, Sunahara F 1987 Cardiovascular effects of high frequency ventilation-the possible involvement of thromboxane. Prostaglandins Leukotrienes Med 28:127-139

24. Hammerman C. Komar K, Meadow W. Strates E 1988 Selective inhibition of thromboxane synthetase reduces group $B$ beta hemolytic streptococci induced pulmonary hypertension in piglets. Dev Pharmacol Ther 11:306-312

25. Runkle B, Goldberg R. Streitfeld M. Clark M, Buron E. Setzer E. Bancalari E 1984 Cardiovascular changes in group B streptococcal sepsis in the piglet: response to indomethacin and relationship to prostacyclin and thromboxane A. Pediatr Res 18:874-878 